\title{
A ATUALIDADE DO RURAL
}

Mariana Miggiolaro Chaguri Universidade de Campinas (Unicamp), Campinas, SP - Brasil. < marianachaguri@gmail.com >

\section{Elide Rugai Bastos} Universidade Estadual de Campinas (Unixamp), Universidade Federal de São Paulo (Unifesp), São Paulo, SP-Brasil. < eliderugai@uol.com.br> http://dx.doi.org/10.1590/ 0102-6445013-026/95

Será possível enfrentar uma análise sobre o Brasil contemporâneo a partir e por meio dos estudos sobre o mundo rural? Neste artigo e nos demais que compõem o dossiê Questão Agrária na Atualidade, arriscamos uma resposta positiva a essa indagação. Partindo de lugares explicativos e sentidos políticos distintos, a reflexão sobre o rural e o agrário acabou por produzir diferentes definições sobre a democracia e os direitos, as quais, no limite, deram suporte a diversificadas compreensões sobre o moderno e a modernização da sociedade brasileira, tematizando seus alcances e limites.

Os estudos sobre essa temática, ao problematizarem a dinâmica das forças sociais em jogo e refletirem sobre a legitimidade do conflito, colocando sob ótica especial a questão da terra, avançaram em direção a possibilidades teóricas e empíricas que permitem afirmar a existência de conexões entre o mundo rural e a concepção/institucionalização dos direitos no Brasil. Sem dúvida, essas relações se ampliaram muito com a inserção da luta pela justiça 
agrária no seio da discussão pelos direitos humanos em âmbito internacional ${ }^{1}$.

$\mathrm{Na}$ análise de tais questões, importa compreender os jogos de força expressos na dinâmica de embates entre a ação coletiva dos movimentos sociais e sindicais e as respostas institucionais do Estado brasileiro, observando que diversos conflitos ou conciliações resultaram em diferentes interpretações e usos políticos ou sociais de temas como o direito à propriedade e à posse da terra, o trabalho no campo e os direitos do trabalhador rural. Em termos teóricos, é preciso construir analiticamente a terra como categoria que instaura a diferença, permitindo, então, respostas variadas aos impasses da democracia brasileira².

Diversidade de questões e de diagnósticos que indicam um acúmulo teórico sobre o tema nos estudos do pensamento social. Nesse sentido, importa recuperar argumentos clássicos sobre a formação da sociedade e do Estado no 14 Brasil, notadamente a formulação de que a onipresença do grande domínio rural teria simplificado a estrutura social, concorrendo para o enfraquecimento ou mesmo para a fragilidade dos laços sociais. Tese de repercussões teóricas e políticas importantes e que marcou fortemente as interpretações sobre o país. Ilustrando,

[...] na amplíssima área de latifúndios agrícolas, só os grandes senhores rurais existem. Fora deles, tudo

\footnotetext{
1 Essa abordagem não é questão desenvolvida neste artigo, embora seja de suma importância para a discussão sobre seus reflexos nos avanços teóricos e empíricos alcançados. Sobre o tema, consultar Canuto e Gorsdorf (2007) e Reis (2012)

2 Em artigo recente, João Marcelo Maia (2013) argumenta que o espaço opera como categoria que instaura a diferença periférica no Brasil em relação às sociedades centrais. $\mathrm{O}$ autor desenvolve, então, a ideia da terra como invenção no pensamento social brasileiro, aprofundando uma perspectiva inaugurada em A terra como invenção: o espaço no pensamento social brasileiro (Maia, 2008). O argumento aqui apresentado está em diálogo com tais perspectivas, embora adote a terra como categoria que permite problematizar a formação da sociedade e do Estado, ponto chave para o debate sobre direitos e sobre a acumulação teórica a partir da perifeira.
} 
é rudimentar, informe, fragmentário. São os grandes domínios como que focos solares: vilas, indústrias, comércios, tudo se ofusca diante de sua claridade poderosa (Vianna, 1952 [1918], v. I, p. 181).

Formulação categórica de Oliveira Vianna que, como dissemos, destaca e confere centralidade à função simplificadora da estrutura social exercida pelo grande domínio rural. O rural emerge como um conjunto de práticas culturais que conformaria padrões específicos de estratificação social e de dominação política que, vistas em conjunto, representariam entraves para a modernização da sociedade e do Estado, restringindo as possibilidades da ação coletiva e sustentando um padrão de dominação política pessoalizado, posto que os mesmos processos que tornavam as relações de solidariedade entre a "aristocracia" e a "plebe rural" frágeis, frouxas, instáveis, desnecessárias no plano econômico (e secundariamente no militar e no religioso) concorreriam para fortalecê-las para efeitos políticos.

$\mathrm{O}$ argumento do autor de Populações meridionais do Brasil é importante para pensar a construção do Estado brasileiro, e se refere a um período desse processo. Em seu argumento, a simplificação da estrutura da sociedade traz

\section{[...] uma das falhas mais graves da nossa organização}

coletiva: a inexistência de uma classe média [...].

É principalmente na pequena propriedade rural [...] que

essa classe tem a sua melhor base (Vianna, 1952, v. I, p. 191).

A argumentação de Vianna está baseada em sua tese da necessidade da organização da nação pelo Estado, mas não especifica claramente como formular políticas em relação à consolidação da pequena propriedade. Em que pese a assertiva do autor de que esta teria o potencial para atração de imigrantes europeus, o que simultaneamente operaria 
em direção da transformação da estrutura social simplificada e pesaria para o branqueamento da sociedade brasileira. Em outros termos, a pertinência da relação entre economia de base agrária e política não é discutida, somente estaria complexada pela introdução de novos atores. Dessa mesma ótica, partiram vários estudos de intérpretes do Brasil.

Numa direção que traz maior rendimento à análise, a pesquisa de Elisa Pereira Reis $(1977,1979,2008)$ parte do princípio da não autonomia do Estado, ou seja, mostra-o "como parte integrante de uma configuração social" (Pereira Reis, 2008, p. 170). Assim, define os principais padrões de sua interação com as outras partes constitutivas da sociedade, tendo como fronteiras o período compreendido entre 1890-1930:

[...] um primeiro deles diz respeito à relação Estadointeresses sociais na qual ganha relevância a função de dominação de classe exercida por aquele. Outro padrão de interação é aquele que confere ao Estado o caráter de mantenedor da ordem social. Finalmente, faz-se mister atentar também para o tipo de interação que coloca o Estado como competidor de interesses sociais particulares e, portanto, como um ator político de soi même (Pereira Reis, 2008, p. 170).

Embora seja arriscado refletir sobre os padrões de forma separada, pois sua articulação tem sentido importante, vamos nos ater ao primeiro, o qual ganha centralidade no argumento que alinha os diferentes artigos deste dossiê. Lembramos que, na República Velha, como a autora denomina o período, são os interesses dos cafeicultores que pesam na definição dos padrões econômico-político-sociais vigentes. Assinalamos, a título de exemplo, o peso da imigração, a modernização da infraestrutura - ferrovias, porto -, o deslocamento espacial do controle da exportação, 
a importância do setor bancário, entre outros fatores. Forma-se um novo complexo econômico-político-social, muito diverso, por exemplo, daquele que fora constituído pelo setor agroindustrial do açúcar. Entre as várias transformações, indicamos a relação entre o rural e o urbano compreendida na base do argumento. Assim, ao referir-se ao alinhamento do financiamento, da produção, da circulação comercial do café, a autora mostra que, mesmo que o objetivo da análise seja a construção do Estado, os dois espaços não podem ser vistos de modo independente.

Embora o tema não seja desenvolvido especificamente, sua importância como princípio analítico coloca um ponto fundamental para a reflexão: estando a relação Estado-sociedade inserida num processo simultâneo de construção, faz-se necessário analisar o sentido que a articulação rural-urbano ganha em cada fase desse desenrolar. Em outros termos, o perfil e a importância que as relações mútuas entre rural e urbano ganham no quadro da definição da questão nacional são dinâmicos e seu sentido sociopolítico deve ser pensado a cada passo do contexto histórico.

Para investigar tais dinamismos, bem como compreender seus sentidos sociopolíticos, um importante recurso analítico está na recuperação do acúmulo teórico em torno de argumentos mais ou menos disjuntivos entre o rural e o urbano que, em articulação com o contexto histórico, acabaram por promover associações entre rural, arcaico e atraso, em oposição a urbano, moderno, progresso.

Nessa perspectiva, os anos de 1950 e 1960 podem ser tomados como um dos mais expressivos momentos de articulação entre processos de mudança social e sua reinterpretação reflexiva pelas ideias. Teses sobre o dualismo estrutural que marcaria não apenas a sociedade brasileira, mas o conjunto das formações sociais latino-americanas nesses anos, ganharam destaque e concorreram para promover associações explicativas entre o rural e o arcaísmo 
que lhe seria inerente. No entanto, também surgiram, no período, guinadas substantivas nas reflexões sobre o rural, fosse a partir das pesquisas sobre a sociedade camponesa ou "mundo rústico", para utilizar nomenclatura formulada por Antonio Candido (1964), fosse a partir de uma inversão metodológica chave que, pouco a pouco, permitiu estudar o rural numa perspectiva menos comportamental e mais política.

Deslocamento importante, na medida em que permite reposicionar não apenas a causalidade associada ao nexo rural/arcaico, urbano/moderno, como também possibilitou a reinterpretação dos processos de mudança social então em curso, dando vazão à variabilidade dos diferentes processos de transformação social e concorrendo para a reavaliação crítica do contexto à luz do debate, por exemplo, sobre as bases sociais da dominação política. Nessa direção, destacamos a proposição de Maria Isaura Pereira 18 de Queiroz, para quem o estudo dos processos de mudança social depende tanto da análise das variações mais amplas de estrutura social quanto do conhecimento específico do lugar ocupado pelos diferentes atores. Assim, a precisão da análise obriga a

[...] conhecer a posição das camadas e dos grupos sociais numa estratificação socioeconômica e política, a fim de compreender, em profundidade, a ação deles - e quem diz ação, refere-se também aos produtos das mesmas. (Pereira de Queiroz, 1978, p. X).

Reconstruindo analiticamente as transformações sociais, seja da política, da economia ou da própria sociedade, a partir da ação social, a autora abre espaço para que o rural ganhe validade explicativa não apenas como antagonista do urbano, mas que emerja como categoria de análise que permite investigar diferentes fenômenos sociopolíticos. 
Afastando-se da essencialização arcaizante, o rural se converte em espaço social que concorre para a produção de laços de solidariedade que ampararam tanto mobilizações sociais como respostas institucionais que convergiram para o alargamento da democracia brasileira, uma vez que disputaram diferentes sentidos, cognitivos e normativos, para as transformações sociais e políticas experimentadas ao longo de diferentes contextos históricos.

Sem abandonar a reflexão sobre os constrangimentos e os limites impostos pelo latifúndio à organização da dinâmica do Estado e da sociedade no Brasil, trata-se, no entanto, de mostrar que o processo de democratização de uma sociedade como a brasileira parece encontrar, vez por outra, caminhos inesperados quando os confrontamos com aqueles trilhados pelas formações sociais clássicas.

É fato conhecido que a questão agrária, principalmente no que diz respeito ao acesso à terra, tem um longo passado, remontando ao processo de colonização do território; também se sabe que a discussão sobre a legislação do trabalho no campo e o direito à organização sindical se levantou nos anos de 1930, e movimentos sociais com perfis variados, colocando como eixo as condições de existência social dos trabalhadores rurais, marcaram a história nacional. Esse processo não ocorre com linearidade e os vaivens das mudanças, os efeitos das mesmas, as modificações resultantes do processo de modernização, as formas de ocupação do território, o autoritarismo que reprimiu movimentos sociais em vários momentos da história, projetos que desalojaram vastos setores da população - as barragens, a transamazônica, como exemplos - colocam em outro patamar a questão da terra e as relações sociais no espaço rural. Novos atores como movimentos quilombolas, movimentos de populações atingidas por remoções forçadas, intersecções entre movimentos camponeses e lutas indígenas, ao lado dos antigos - sindicatos, movimentos camponeses históricos etc. - retomaram e reabriram o 
debate, apoiados por intelectuais, pela Igreja Católica, por organizações da sociedade civil, nacionais e estrangeiras, por organismos multilaterais etc. Esses elementos impõem, como dissemos, a constante retomada da ótica do lugar que assume a agenda política sobre a terra, o lugar social e político dos diferentes atores, as estratégias assumidas pelos movimentos sociais, a aceitação ou não pelo conjunto da sociedade dos conflitos denunciados.

Como apontamos anteriormente, os vários estudos sobre essas transformações avançaram em direção a possibilidades teóricas e empíricas, mostrando como a própria definição do conflito pelos atores permitiu a incorporação de denominações que passaram a constituir-se como categorias analíticas novas. Nem sempre os termos são novos, mas sua aplicação abrange sentidos e/ou significados diferentes. Ilustramos com a utilização que McAdam, Tarrow e Tilly $(2009 \text { [1996] })^{3}$ fazem da expressão "confronto político". Os 20 autores apontam a existência de uma conotação conferida à mesma - sua forma coletiva, a oposição de interesses entre os atores que apresentam as reivindicações, a diversidade pela qual estas se apresentam. Mais, indicam que o confronto "depende da mobilização, da criação de meios e de capacidades para a interação coletiva” (McAdam, Tarrow e Tilly, 2009, pp. 11-12). Assim, a expressão passa a abranger mobilizações que se apresentam sob várias denominações: movimentos sociais, revoluções, ciclos de protestos, ações coletivas, mobilizações sociopolíticas ${ }^{4}$.

Vale assinalar, aqui, embora seja uma suposição nossa sobre o texto dos autores, a ampliação que conferem ao

\footnotetext{
3 O texto faz parte dos delineamentos teóricos para um projeto administrado pelo Center for Advanced Studies in the Behavior Sciences, que agregou vários outros autores.

4 Embora os autores nomeassem apenas o que indicam como "conhecida tríade, movimentos sociais, revoluções e ações coletivas", tomamos a liberdade de indicar outras denominações, mesmo porque algumas delas são recentemente exploradas pela imprensa brasileira.
} 
termo político. Embora esse sentido faça parte do debate contemporâneo das ciências sociais, muitas vezes os conceitos utilizados para a definição das mobilizações coletivas sofrem de um vício institucionalista. Isto é, a importância das mesmas no embate político, a possibilidade de considerarem-se os atores das mesmas como capazes de atuar na definição da agenda de encaminhamento das soluções aos problemas só é reconhecida se definido seu lugar institucional formal ou partidário. Em outras palavras, aquilo que pode parecer apenas uma mudança semântica no campo da sociologia ou das ciências sociais ultrapassa esses limites e permite uma nova visão sobre o lugar e o papel dos atores sociais anteriormente considerados sem importância na definição não só das políticas sociais, mas da "grande política".

A aceitação da ampliação da noção de política diz respeito diretamente à formulação de Tilly (1978) sobre como o confronto coletivo assume a forma de repertórios. Estes, que são o modo pelo qual se estabelece a interação entre os atores de uma mobilização, indicam também como aqueles que apresentam as reivindicações percebem a perda de operacionalidade das formas consagradas de reiteração da vida social e buscam alternativas à crise. É a busca para superá-la que leva aqueles que denunciam o conflito e percebem as dificuldades para superá-lo dentro dos velhos quadros sociais ao reordenamento das referências. Para os atores que tomam consciência dos problemas e não se contentam com a reiteração das condições sociais de existência, a busca de instauração de novas condições de vida social obriga à formulação de novas formas de ação. É claro que não se trata de procedimento linear, mas sim de um processo evidentemente marcado por tensões que opõem inovações e permanências, como o é todo processo de mudança social. De forma concreta, os artigos que compõem este dossiê abordam as diferentes faces dessa questão. 


\section{Os novos atores da questão agrária}

No marco da Constituição federal de 1988, o contexto histórico compartilhado direta ou indiretamente pelos artigos aqui reunidos, observam-se atores sociais e demandas políticas chaves para a reflexão sobre os processos constitutivos da cidadania no Brasil. Desse modo, é possível observar embates políticos e sociais que deram suporte a diferentes mobilizações sociais, estratégias de luta e ações políticas, orientando diferentes transformações na normatização dos direitos no país.

Idas e vindas que ganham complexidade à medida que se avança, teórica e empiricamente, no reconhecimento da pluralidade de atores e de demandas que compõem e articulam as condições sociais, a partir das quais emerge a legitimidade do conflito enquanto dimensões constitutivas da democracia e da cidadania.

Os argumentos apresentados por Nashieli Loera em "Mecanismos sociais da reforma agrária em São Paulo pelo 22 viés etnográfico" e por Marcelo Rosa e Camila Penna em "Estado, movimentos e a produção da reforma agrária no Brasil: reflexões a partir do Incra" observam que, para além de arranjos identitários, os sem-terras emergem como categoria que institucionalizou não apenas uma forma de demandar terra no Brasil, mas, especialmente, teria institucionalizado uma forma de negociação com o Estado.

Os dois artigos dialogam com pesquisas anteriores de seus autores (cf. Loera, 2009; Rosa, 2011; Castro, 2013), concorrendo para aprofundar os estudos sobre os alcances e os limites das demandas por terra no Brasil a partir e por meio daquilo que Lygia Sigaud (2000, p. 91) definiu como "forma acampamento", isto é, uma

[...] forma levada [...] pelo MST e difundida com a colaboração dos sindicalistas, uma afirmação simbólica cujos significados eram compartilhados pelos diferentes indivíduos envolvidos nos acampamentos e por isso mesmo eficaz. 
Nas idas e vindas entre movimentos e Estado, a compreensão do processo de construção de repertórios da ação coletiva (cf. Tilly, 2006) passa, como demonstra o artigo de Marcelo Rosa e Camila Penna Castro, não apenas pela capacidade dos movimentos sociais de influenciar políticas de reforma agrária, mas demanda também atenção ao papel da burocracia, notadamente, com a interação entre demandantes de terra e servidores do Incra.

A atuação do movimento acabou por construir categorias, como "acampamento", "sem-terra" e "movimento", com as quais o Estado trabalha [...], que foram internalizadas e são atualizadas nas práticas cotidianas dos servidores do Incra (p. 64 deste dossiê).

Se os conflitos sociais e políticos envolvidos nas reclamações pela posse e uso da terra conectam as estratégias de diferentes movimentos sociais às próprias práticas institucionais do Estado, o recurso empírico ao rural se torna, também, um desafio à teoria por permitir indagar as transformações do próprio Estado brasileiro e de suas instituições.

Caminhos que estão presentes no artigo "Paradoxos do sindicalismo brasileiro: a CUT e os trabalhadores rurais", de Iram Jácome Rodrigues e Mario Henrique Guedes Ladosky. Indagando as razões, políticas e sociológicas, que fazem com que a base sindicalizada da CUT abrigue um contingente bastante expressivo de associados ligados a atividades produtivas do setor rural, os autores demonstram não apenas a vitalidade e a atualidade do trabalho no campo, como também indicam novos caminhos para o complexo processo de afirmação política dos direitos do trabalhador rural.

No entanto, se a miríade de temas e problemas envolvidos na articulação entre movimentos sociais, sindicatos e Estado concorrem para reconstruir teoricamente a empiria do rural brasileiro contemporâneo, importa observar que 
a atualidade do rural como chave interpretativa do Brasil implica, também, o acionamento de outras categorias e conceitos, orientados para a investigação da dinâmica da agricultura e dos agricultores em suas estratégias de reprodução social.

Se as discussões sobre as novas ruralidades organizaram aspectos importantes do debate (cf. Carneiro, 1998; Ferreira, 2002), o artigo de Abel Cassol e Sergio Schneider, "Produção e consumo de alimentos: novas redes e atores" destaca a importância de investigar e, especialmente, incorporar os consumidores como atores sociais das análises sobre a produção e reprodução da agricultura familiar. Assim, se, como propõem os autores, os mercados locais "são formas de inclusão social dos pequenos agricultores", abre-se espaço para investigar a diversidade de formas de organização que concorrem para estruturar a pequena agricultura e, por esta via, oferecer uma diversidade de respostas locais às 24 práticas de produção e de alimentação.

Percorrendo uma extensa gama de problemas, este dossiê pretende contribuir não apenas para demonstrar a vitalidade empírica do rural brasileiro, mas, especialmente, para indicar a atualidade das questões colocadas e construídas a partir da reflexão sobre os processos rurais contemporâneos.

\section{Mariana Miggiolaro Chaguri}

é professora do Departamento de Sociologia da Universidade de Campinas (Unicamp) e diretora do Centro de Estudos Rurais (Ceres - IFCH/Unicamp).

\section{Elide Rugai Bastos}

é professora titular do Departamento de Sociologia da Unicamp e pesquisadora sênior da Universidade Federal de São Paulo (Unifesp). 


\section{Bibliografia}

CANDIDO, A. 1964. Os parceiros do rio Bonito: estudo sobre o caipira paulista e a transformação dos seus meios de vida. Rio de Janeiro: José Olympio.

CANUTO, A.; GORSDORF, L. 2007. "Direito humano à terra: a construção de um marco de resistência às violações”. In: RECH, D. (coord.). Direitos humanos no Brasil 2: diagnóstico e perspectivas. Rio de Janeiro: Ceris; Mauad.

CARNEIRO, M. J. 1998. "Ruralidade: novas identidades em construção". Estudos Sociedade e Agricultura, n. 11, pp. 53-75.

CASTRO, C. P. 2013. Conexões e controvérsias no INCRA de Marabá: o Estado como um ator heterogêneo. Tese de doutorado em Sociologia. Brasília, DF: UnB.

FERREIRA, A. D. D. 2002. "Processos e sentidos sociais do rural na contemporaneidade: indagações sobre algumas especificidades brasileiras”. Estudos Sociedade e Agricultura, n. 18, pp. 28-46.

LOERA, N. 2009. Tempo de acampamento. Tese de doutorado em Antropologia Social. Campinas, SP: Unicamp.

MAIA, J. M. E. 2008. A terra como invenção: o espaço no pensamento social brasileiro. Rio de Janeiro: Jorge Zahar.

. 2013. "A imaginação da terra: o pensamento brasileiro e a condição periférica”. Tempo Social, v. 25, pp. 79-97.

MARTINS, J. de S. 1981. Os camponeses e a política no Brasil. Petrópolis: Vozes.

MCADAM, D.; TARROW, S.; TILLY, C. 2009 [1996]. "Para mapear o confronto político”. Trad. Ana Maria Sallum. Lua Nova, n. 76, pp. 11-48.

PEREIRA DE QUEIROZ, M. I. 1978. Cultura, sociedade rural, sociedade urbana no Brasil: ensaios. Rio de Janeiro: Livros Técnicos e Científicos; São Paulo: Edusp.

PEREIRA REIS, E. 1977. Conservative modernization in Brazilian agriculture: the post-abolition plantation. Houston: Latin American Studies Association.

. 1979. The agrarian roots of authoritarian modernization in Brazil, 18801930. PhD dissertation, Massachusetts: MIT.

2008. "Interesses agroexportadores e construção do Estado - Brasil, 1890-1930”. In: SORJ, B.; CARDOSO, F. H.; FONT, M. (orgs.). Economia e movimentos sociais na América Latina. Rio de Janeiro: Edelstein de Pesquisa Social.

REIS, R. R. 2012. "O direito à terra como um direito humano: a luta pela reforma agrária e o movimento de direitos humanos no Brasil". Lua Nova, n. 86, pp. 89-112. 
ROSA, M. 2011. O engenho dos movimentos: reforma agrária e significação social na zona canavieira de Pernambuco. Rio de Janeiro: Garamond.

SIGAUD, L. 2000. "A forma acampamento: notas a partir da versão pernambucana”. Novos Estudos Cebrap, n. 58, pp. 73-92.

SIGAUD, L.; ERNANDEZ, M.; ROSA, M. C. (orgs.). 2010. Ocupações e acampamentos: sociogênese das mobilizações por reforma agrária no Brasil. Rio de Janeiro: Garamond.

TILLY, C. 1978. From mobilization to revolution. Reading. Massachusetts: Addison Wesley. 2006. Regimes and repertoires. Chicago: Chicago Press.

VIANNA, O. 1952 [1918]. Populações meridionais do Brasil: história organização - psicologia. Rio de Janeiro: José Olympio. 2v. 


\section{A ATUALIDADE DO RURAL}

\section{MARIANA MIGGIOLARO CHAGURI ELIDE RUGAI BASTOS}

Resumo: $\mathrm{O}$ artigo busca mostrar que a partir de lugares explicativos e sentidos políticos diversos, a reflexão sobre o rural e o agrário acabou por produzir diferentes definições sobre a democracia e os direitos, as quais, no limite, deram suporte a diferenciadas compreensões sobre o moderno e a modernização da sociedade brasileira. Aponta, ainda, como as novas reflexões avançaram em direção a possibilidades teóricas e empíricas que permitem afirmar a existência de conexões entre o mundo rural e a questão dos direitos no Brasil.

Palavras-chave: Rural; Movimentos Sociais; Estado; Pensamento Social.

\section{REVISITING THE RURAL}

Abstract: This article shows that the reflection on the rural and the agrarian produced different definitions of democracy and rights. Differences that, at the limit, have supported differentiated insights into the modern and the modernization of the Brazilian society. The article also points out how new ideas have moved theoretical and empirical possibilities that allow us to affirm the existence of connections between the rural world and the question of rights in Brazil.

Keywords: Rural; Social Movements; State; Social Thought.

Recebido: 10/06/2015 Aprovado: 21/06/2015 